\title{
Air pressure propagation through Wind Cave and Jewel Cave: How do pressure waves travel through barometric caves?
}

\author{
Annika K. Gomell (D ${ }^{1 *}$, Daniel C. Austin (D) ${ }^{2}$, Marc J. Ohms (D) ${ }^{3}$, and Andreas Pflitsch (D) ${ }^{1}$ \\ ${ }^{1}$ Ruhr-University Bochum, Institute of Geography, Climatology of Extreme Environments, Universitätsstraße 150, 44801 Bochum, Germany \\ ${ }^{2}$ Jewel Cave National Monument, 11149 U.S. Highway 16, Custer, SD 57730, USA \\ ${ }^{3}$ Wind Cave National Park, 26611 U.S. Highway 385, Hot Springs, SD 57747, USA
}

\begin{abstract}
In barometric caves, air pressure gradients between the outside atmosphere and the cave induce strong bidirectional compensating currents, which control almost all elements of speleoclimatology, including air temperature, humidity, and $\mathrm{CO}_{2}$ dynamics. Therefore, this study set out to investigate air pressure propagation through Wind Cave and Jewel Cave two major barometric cave systems in the Black Hills of South Dakota, USA. Based on highresolution air pressure data from both the surface and several measurement sites inside the caves, four systematic changes of pressure waves during their journey through the caves and their related speleoclimatological processes were identified and discussed: Compared to the outside atmosphere, the pressure signals within Wind Cave and Jewel Cave showed (1) an absolute displacement due to different altitudes of the measuring sites, (2) a delay related to the travel times of the pressure wave to the measuring sites, (3) a smoothing effect, and (4) a damping effect due to long response times of the caves to external pressure changes. The spatial distribution of the changes observed in this study shows that for Wind Cave, the cave opening and the narrow entrance area represent the main obstacle for pressure propagation, while for Jewel Cave, the deep areas have the greatest influence on the development of air pressure gradients. Our analyses provide completely new insights into the processes and mechanisms inside barometric caves, which will significantly contribute to the understanding of pressure-related airflow dynamics and all related elements of speleoclimatology.
\end{abstract}

Keywords: Speleoclimatology, barometric cave, Wind Cave, Jewel Cave, air pressure

Received 1 June 2021; Revised 31 August 2021; Accepted 3 September 2021

Citation: $\quad$ Gomell A.K, Austin D.C., Ohms M.J., Pflitsch A., 2021. Air pressure propagation through Wind Cave and Jewel Cave: How do pressure waves travel through barometric caves? International Journal of Speleology, 50(3), 263-273. https://doi.org/10.5038/1827-806X.50.3.2393

\section{INTRODUCTION}

Numerous studies agree on the central importance of speleoclimatology as a critical component of the caves' internal environment for flora, fauna, microorganisms, karst processes, and hydrogeology (e.g., Tuttle \& Stevenson, 1977; De Freitas \& Littlejohn, 1987; Dublyansky \& Dublyansky, 1998; Kłys \& Wołoszyn, 2005; De Freitas, 2010; Mammola et al., 2015; Vieten et al., 2016). Nevertheless, the microclimatology of caves has long been a neglected aspect of both theoretical and applied climate research (De Freitas et al., 1982; Ravbar $\&$ Kosutnik, 2014). However, nowadays technological progress in measurement techniques and power supply allows not only qualitative local observations and descriptions of cave climatology but also long-term high-resolution quantitative measurements and their analysis, thus providing completely new insights into the processes and mechanisms involved.
A thorough understanding of the driving factors of underground airflow is fundamental for almost all elements of speleoclimatology, including air temperature, humidity, and $\mathrm{CO}_{2}$ dynamics (SánchezCañete et al., 2013; Breitenbach et al., 2015) as well as for management and conservation purposes (Fernández-Cortés et al., 2006; Russell \& MacLean, 2008; Lario \& Soler, 2010). In contrast to the majority of caves, in which temperature gradients between the outside atmosphere and the air inside the cave drive convective compensating air currents (Moore \& Nicholas, 1964; Bögli, 1980), airflow in barometric caves is induced by air pressure gradients between the surface and the cave which result from atmospheric pressure variations (Moore \& Nicholas, 1964; Conn, 1966; Pflitsch et al., 2010).

In small to medium-sized cave systems or even in larger cave systems with large or numerous openings, atmospheric pressure fluctuations are transmitted 
directly into the cave. Consequently, no pressure gradient can develop between the outside atmosphere and the cave and no barometric currents are induced. If, however, the cross-section of a cave opening is very small compared to the cave volume behind, the exchange of air between the outside atmosphere and the inside of these caves is strongly limited. Thus, no rapid pressure equalization can take place. Therefore, pressure gradients between the outside atmosphere and the cave develop, resulting in barometric compensating currents. Figure 1 shows this process in a schematic idealized barometric cave: Assuming equal pressure between the outside atmosphere and the air inside the cave, there are no compensating currents between the two air masses (a). If, however, regional pressure increases due to an approaching anticyclone, a positive pressure gradient between the outside atmosphere and the air inside the cave will develop. Depending on the response time of the cave, which is increasing with volume and decreasing with the diameter of the opening, the pressures of the two air masses cannot directly equalize, leading to relative negative pressure inside the cave (b). This gradient then induces compensating air currents directed into the cave, which continue until the pressure conditions reach equilibrium. If, on the other hand, atmospheric pressure decreases again, relative underpressure of the outside atmosphere will induce compensating air currents directed out of the cave (c). This process again continues until external and internal pressures have equalized.

Pflitsch et al. (2010) provide a detailed summary of the current state of knowledge on the origin and characteristics of barometric airflow as well as its consequences for speleoclimatology and a comparison to convective airflow. Their fundamental research forms the basis of this study. The basic principles of barometric airflow also allow the calculation of the caves' volumes and the exploration of possible connections between different cave systems (Conn, 1966; Ringeis et al., 2007; Pflitsch \& Ringeis, 2009).

Until today, there have been no studies on pressure propagation through barometric caves supported by quantitative data from both the outside atmosphere and the caves. Thus, this study set out to gain a better understanding of pressure-related speleoclimatological processes. High-resolution air pressure data inside and outside Wind Cave and Jewel Cave - two major barometric cave systems in the Black Hills of South Dakota - are compared to identify both similarities and systematic differences between air pressure signals of the outside atmosphere and the caves. Based on these findings, the involved speleoclimatological processes affecting air pressure waves inside barometric caves are explored with regard to cave morphology. Furthermore, the hypothesis that the strength of the changes depends on the distance to the cave opening is tested.

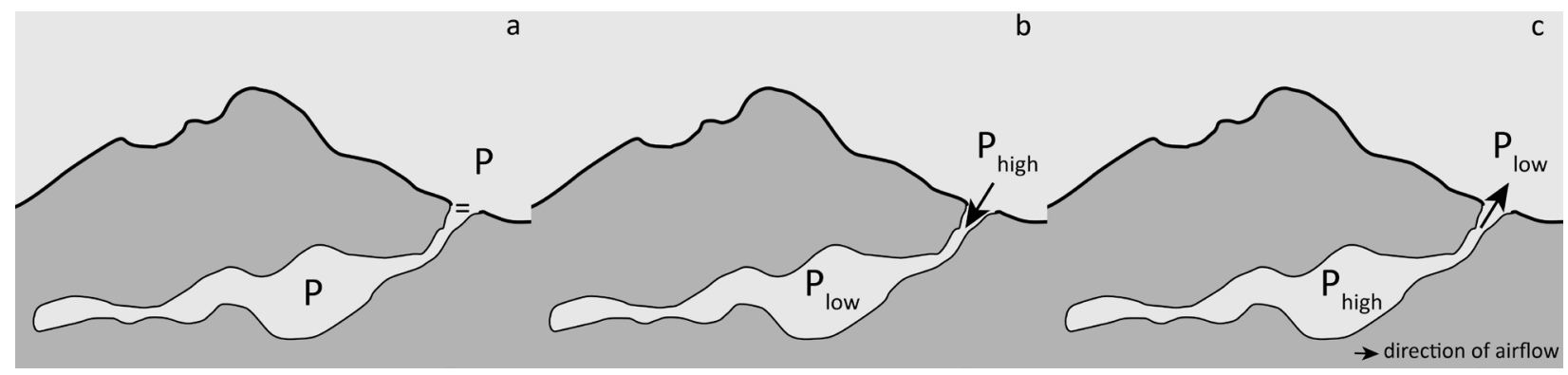

Fig. 1. Schematic representation of an idealized barometric cave system for three different pressure and airflow situations: a) equalized pressure between air inside the cave and outside atmosphere: no compensating airflow; b) relative atmospheric overpressure: compensating airflow into the cave, and c) relative atmospheric underpressure: compensating airflow out of the cave.

\section{STUDY SITES}

Wind Cave and Jewel Cave are two large barometric cave systems located in the Black Hills in South Dakota and were discovered in 1881 and 1900, respectively. Both caves are extremely complex three-dimensional network mazes in Carboniferous limestone and dolomite of the so-called Mississippian Madison Formation - also known as Pahaspa limestone (Bakalowicz et al., 1987; Palmer \& Palmer, 1989). Their formation took place in several stages over the course of more than 300 million years, with significant parts being formed in the phreatic zone after the uplift of the Black Hills 40 - 60 million years ago (KellerLynn, 2009; Palmer, 2016; Palmer et al., 2016).

With a currently known length of $336.9 \mathrm{~km}$ and a depth of $253.6 \mathrm{~m}$, Jewel Cave is the third-longest cave in the world (as of May 2021). The "Historic Entrance" is located $1,614 \mathrm{~m}$ above sea level $\left(43^{\circ} 43^{\prime} 46^{\prime \prime} \mathrm{N}\right.$ $\left.103^{\circ} 49^{\prime} 46^{\prime \prime} \mathrm{W}\right)$. Wind Cave, on the other hand, has a known length of $248.2 \mathrm{~km}$ and a depth of $193.9 \mathrm{~m}$ (as of May 2021), making it currently the seventh longest cave in the world. Its "Natural Entrance" is located $1,244 \mathrm{~m}$ above sea level $\left(43^{\circ} 33^{\prime} 23^{\prime \prime} \mathrm{N} 103^{\circ} 28^{\prime} 43^{\prime \prime} \mathrm{W}\right)$.

Despite the short distance between their openings of only $50 \mathrm{~km}$, Wind Cave and Jewel Cave display very different characteristics: Wind Cave is an extremely dense cave system with regard to passage volume per rock volume. Its rather narrow passages are comparatively irregular and rugged, with walls being abundantly covered with boxwork (i.e., speleothems with box-like structures formed by thin calcite plates). Jewel Cave, in contrast, is characterized by comparably wider passages and smoother cave walls, partially covered with a 15-cm-thick layer of calcite crystals - the eponymous Jewels (Palmer et al., 2016). Since their discovery, both caves were known for their strong bidirectional air currents. In the 1960s, Conn (1966) identified those to be of barometric origin. 
Table 1. Comparative pressure measurement time series conducted in Wind Cave and Jewel Cave between 2017 and 2020. The table is organized in chronological order, sorted by investigated cave.

\begin{tabular}{|l|c|c|c|c|}
\hline \multicolumn{1}{|c|}{ Cave } & Locations & Measurement period & $\begin{array}{c}\text { Temporal } \\
\text { resolution }\end{array}$ & $\begin{array}{c}\text { Number of } \\
\text { measurements }\end{array}$ \\
\hline Wind Cave & Surface - Crossroads & $\begin{array}{c}08 / 11 / 201709: 19: 00- \\
10 / 19 / 201704: 43: 00\end{array}$ & $10 \mathrm{~s}$ & 594505 \\
\hline Wind Cave & Surface - Lakes & $\begin{array}{c}12 / 16 / 201800: 00: 00- \\
06 / 20 / 201910: 49: 20\end{array}$ & $20 \mathrm{~s}$ & 805469 \\
\hline Wind Cave & Surface - Elevator & $\begin{array}{c}07 / 08 / 201921: 47: 00- \\
11 / 07 / 201915: 31: 40\end{array}$ & $20 \mathrm{~s}$ & 525915 \\
\hline Wind Cave & Surface - Crossroads & $\begin{array}{c}09 / 23 / 202000: 00: 00- \\
11 / 03 / 202000: 00: 00\end{array}$ & $20 \mathrm{~s}$ & 177121 \\
\hline Wind Cave & Surface - Pearly Gates - Crossroads - & $\begin{array}{c}10 / 16 / 202000: 00: 00- \\
11 / 03 / 202000: 00: 00\end{array}$ & $20 \mathrm{~s}$ & $77761^{*}$ \\
\hline Jewel Cave & Surface - Spooky Hollow & $\begin{array}{c}12 / 18 / 201711: 50: 40- \\
04 / 13 / 201808: 26: 40\end{array}$ & $20 \mathrm{~s}$ & 502669 \\
\hline Jewel Cave & Surface - Deep Camp & $\begin{array}{c}11 / 03 / 201800: 00: 00- \\
12 / 11 / 201805: 19: 40\end{array}$ & $20 \mathrm{~s}$ & 165120 \\
\hline
\end{tabular}

*Measurements for "Surface" and "Crossroads" are also included in the measurement above.
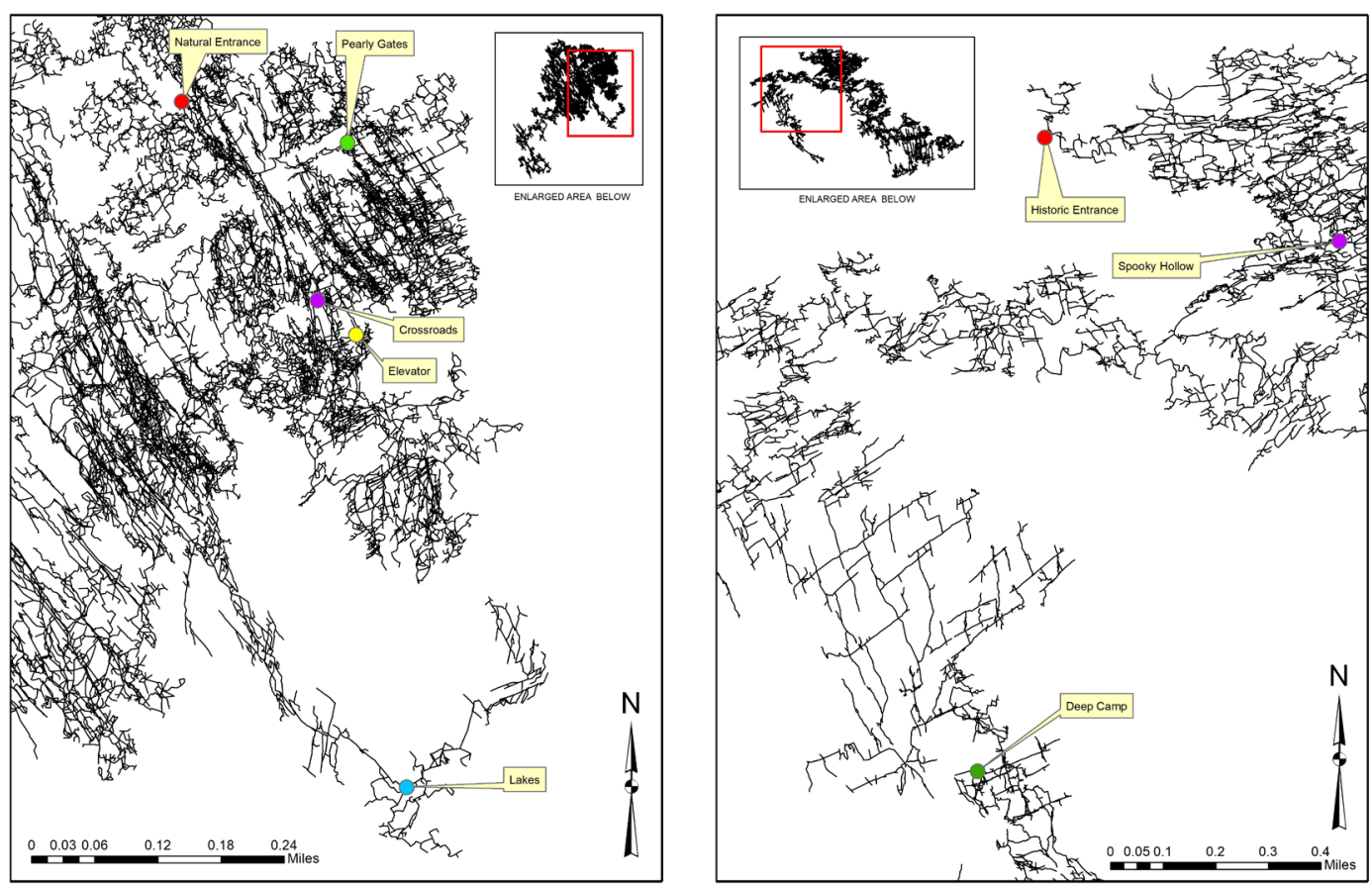

Fig. 2. Ground plans of a) Wind Cave and b) Jewel Cave showing the positions of all measurement locations inside the caves.

\section{MEASUREMENTS}

An extensive long-term measurement program was initiated in August 2017 to investigate the courses of air pressure inside and outside the caves. Highresolution monitoring of air pressure was conducted at four locations inside Wind Cave, two locations inside Jewel Cave, and at the respective surface sites using a Baro-Sensor (Drießen und Kern DK323/391; measurement range 10 to $1300 \mathrm{hPa}$, resolution 0.1 $\mathrm{hPa}$, accuracy $\pm 1.5 \mathrm{hPa}$ ). Pressure data were recorded simultaneously at 10 to $20 \mathrm{sec}$ intervals between 2017 and 2020 as instantaneous values. All comparative measurement series are summarized in Table 1 . The different durations of the measurement series are due to moisture-related technical failures of the measuring instruments.

The surface sensors were placed in the administrative offices of Wind Cave National Park and Jewel Cave National Monument, respectively. In increasing order according to their distance from the cave opening, the positions inside Wind Cave include Pearly Gates, Crossroads, Elevator, and Lakes; those inside Jewel Cave include Spooky Hollow and Deep Camp. The positions of all measurement sites inside the caves are displayed in Figure 2.

A comparative analysis between office use times during the day and nighttime hours showed no influence of HVAC operation or other activities during office use on surface air pressure measurements.

\section{RESULTS AND DISCUSSION}

\section{Course of air pressure inside the cave compared to atmospheric pressure variations}

The high-resolution monitoring data allow comparing surface and cave air pressure conditions. In general, the courses of air pressure at the surfaces and inside both Wind Cave and Jewel Cave are quite similar as the surface atmospheric pressure waves are transmitted into the caves through their openings 
(Fig. 3). Thus, correlation analysis based on Pearson's correlation coefficient of surface and cave air pressure gives $\mathrm{R}$ values of 0.97106 (Pearly Gates) to 0.9895 (Crossroads) for Wind Cave and 0.84037 (Deep Camp) to 0.99474 (Spooky Hollow) for Jewel Cave (Table 2).

Contrary to expectations, the study for Wind Cave does not find a general decrease in correlation of the surface and cave pressure signals with increasing distance of the measurement points from the cave entrance. Thus, the lowest correlation of all simultaneous internal and external pressure signals does not occur at the measuring site Lakes very deep inside the cave, but at Pearly Gates, a site much closer to the cave entrance (Fig. 2). Although the highly complex three-dimensional maze structure of Wind Cave prohibits a precise determination of the
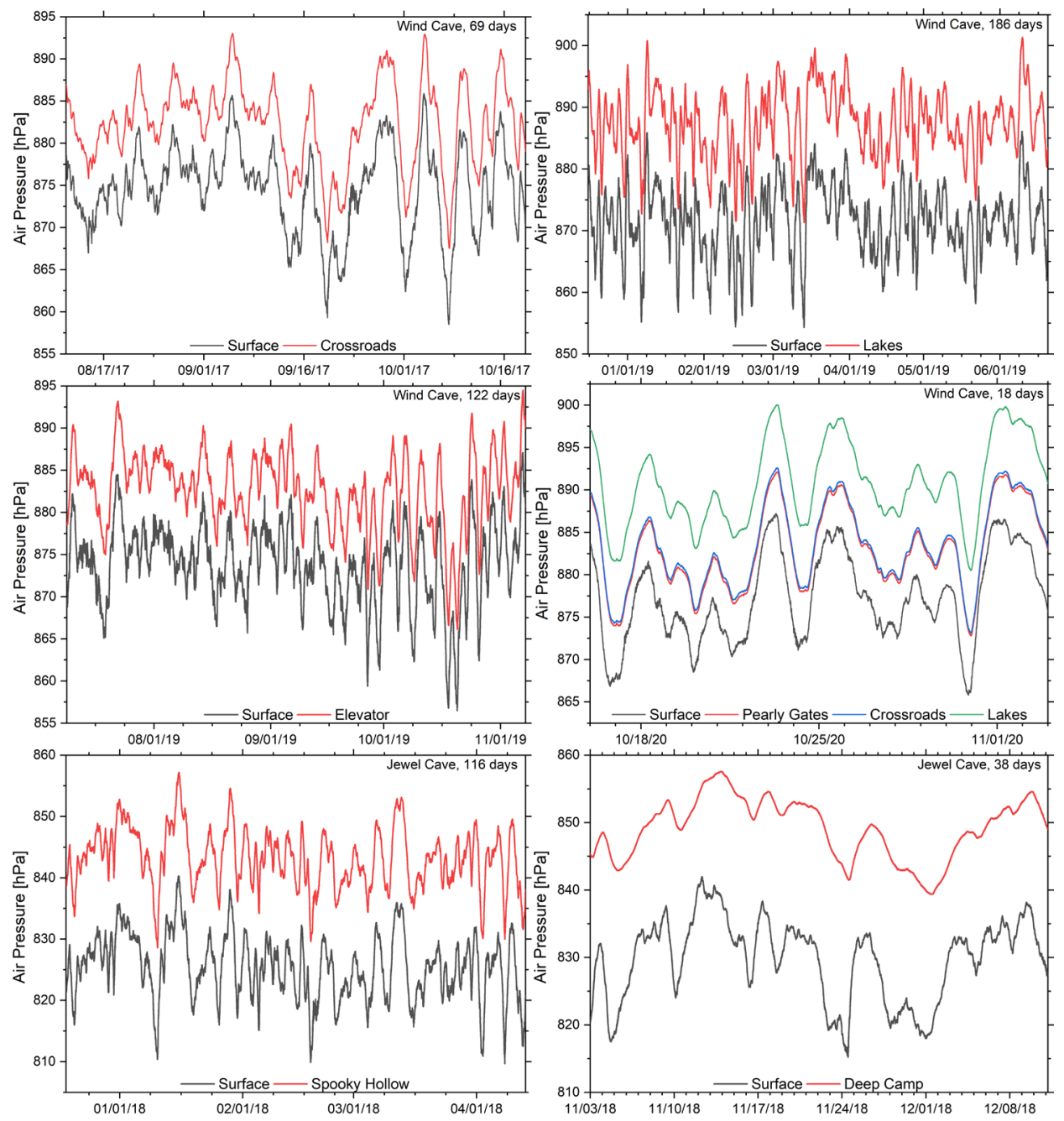

Fig. 3. Simultaneous high-resolution air pressure measurements at the surface and various sites inside Wind Cave and Jewel Cave. Note the different durations of the measurement periods.

distance of the measurement points from the cave entrance, it is possible to rank the measuring points according to their position. Correlation analysis based on the position of the measuring sites inside the cave yields a Spearman correlation coefficient of only 0.265 , supporting the result that the position within the cave is not a decisive factor for the correlation of the internal and external pressure signals. For Jewel Cave, however, a completely different picture emerges: Here, the correlation at Deep Camp, located deep inside the cave, is considerably lower than it is at Spooky Hollow, located in the upper part of the cave (Fig. 2).

Despite the general high correlations and great similarities between surface and cave air pressure signals, their comparison also demonstrates four systematic differences, which can be connected to speleoclimatological processes. An in-depth analysis of the pressure data provides interesting insights into processes acting on pressure waves as they travel through Wind Cave and Jewel Cave.

\section{Absolute air pressure difference}

The most apparent difference between the air pressure signals inside the caves and on the surface is that in all measurement series, the air pressure inside the cave is always higher than simultaneous outside atmospheric pressure, where the absolute difference seems to be approximately constant for each measurement site (Fig. 3). Thus, for Wind Cave, descriptive statistics (Table 2) show that the average values of surface air pressure vary between 868.7 and $877.3 \mathrm{hPa}$, while inside the caves, they range from 872.8 to $890.8 \mathrm{hPa}$ depending on the location. The extreme values of the air pressure measurement series behave very similarly: The minima of air pressure within the caves lie between 863.5 and $880.5 \mathrm{hPa}$, those on the surface between 854.3 and $865.8 \mathrm{hPa}$; the maxima accordingly between 883.3 and $901.3 \mathrm{hPa}$ (cave) and 880.3 and $887.2 \mathrm{hPa}$ (surface). A similar pattern is observed for Jewel Cave, with all pressure 
Table 2. Basic descriptive statistics of air pressure monitoring data from Wind Cave and Jewel Cave. and the respective surface sites in the observed period.

\begin{tabular}{|c|c|c|c|c|c|c|c|c|}
\hline Locations & $\begin{array}{c}\text { P mean } \\
{[\mathrm{hPa}]}\end{array}$ & $\begin{array}{l}\text { P Min } \\
{[\mathrm{hPa}]}\end{array}$ & $\begin{array}{l}\text { P Max } \\
{[\mathrm{hPa}]}\end{array}$ & $\begin{array}{c}\text { P Range } \\
\text { [hPa] }\end{array}$ & $\begin{array}{l}\text { P IQR } \\
{[\mathrm{hPa}]}\end{array}$ & $\begin{array}{c}\text { P St. Dev. } \\
{[\mathrm{hPa}]}\end{array}$ & $\begin{array}{c}\text { P Variance } \\
{\left[\mathrm{hPa}^{2}\right]}\end{array}$ & Correlation $\mathbf{R}$ \\
\hline $\begin{array}{l}\text { Surface - } \\
\text { Crossroads }\end{array}$ & $\begin{array}{l}874.4 \\
882.3 \\
\end{array}$ & $\begin{array}{l}858.5 \\
867.5 \\
\end{array}$ & $\begin{array}{l}885.9 \\
893.0 \\
\end{array}$ & $\begin{array}{l}27.4 \\
25.5 \\
\end{array}$ & $\begin{array}{l}6.2 \\
6.0 \\
\end{array}$ & $\begin{array}{l}5.1 \\
5.0 \\
\end{array}$ & $\begin{array}{c}26.0 \\
24.7^{*} \\
\end{array}$ & $R=0.990$ \\
\hline $\begin{array}{l}\text { Surface - } \\
\text { Lakes }\end{array}$ & $\begin{array}{l}871.6 \\
887.4\end{array}$ & $\begin{array}{l}854.3 \\
871.3\end{array}$ & $\begin{array}{l}886.1 \\
901.3\end{array}$ & $\begin{array}{l}31.8 \\
30.0\end{array}$ & $\begin{array}{l}7.4 \\
7.0 \\
\end{array}$ & $\begin{array}{l}5.6 \\
5.4\end{array}$ & $\begin{array}{c}31.4 \\
29.0^{*}\end{array}$ & $\mathrm{R}=0.981$ \\
\hline $\begin{array}{l}\text { Surface - } \\
\text { Elevator }\end{array}$ & $\begin{array}{l}873.8 \\
882.7 \\
\end{array}$ & $\begin{array}{l}856.5 \\
866.1 \\
\end{array}$ & $\begin{array}{l}887.1 \\
894.5\end{array}$ & $\begin{array}{l}30.6 \\
28.4\end{array}$ & $\begin{array}{l}5.9 \\
5.7 \\
\end{array}$ & $\begin{array}{l}4.8 \\
4.6\end{array}$ & $\begin{array}{c}23.1 \\
21.0^{*} \\
\end{array}$ & $\mathrm{R}=0.980$ \\
\hline $\begin{array}{l}\text { Surface - } \\
\text { Crossroads }\end{array}$ & $\begin{array}{l}876.2 \\
882.4\end{array}$ & $\begin{array}{l}860.1 \\
867.5\end{array}$ & $\begin{array}{l}888.0 \\
893.9\end{array}$ & $\begin{array}{l}27.9 \\
26.4\end{array}$ & $\begin{array}{l}7.3 \\
7.0 \\
\end{array}$ & $\begin{array}{l}5.5 \\
5.2\end{array}$ & $\begin{array}{l}30.5 \\
27.1^{*}\end{array}$ & $\mathrm{R}=0.979$ \\
\hline $\begin{array}{l}\text { Surface - } \\
\text { Pearly Gates - } \\
\text { Crossroads - } \\
\text { Lakes }\end{array}$ & $\begin{array}{l}877.3 \\
883.0 \\
883.4 \\
890.8\end{array}$ & $\begin{array}{l}865.8 \\
872.8 \\
873.1 \\
880.5\end{array}$ & $\begin{array}{l}887.2 \\
892.2 \\
892.6 \\
900.0\end{array}$ & $\begin{array}{l}21.4 \\
19.4 \\
19.5 \\
19.5\end{array}$ & $\begin{array}{l}7.8 \\
7.2 \\
7.2 \\
7.4\end{array}$ & $\begin{array}{l}5.2 \\
4.8 \\
4.8 \\
4.9\end{array}$ & $\begin{array}{l}26.8 \\
23.4^{*} \\
23.4^{*} \\
24.0^{*}\end{array}$ & $\begin{array}{l}R=0.971 \\
R=0.973 \\
R=0.971\end{array}$ \\
\hline $\begin{array}{l}\text { Surface - } \\
\text { Spooky Hollow }\end{array}$ & $\begin{array}{l}825.4 \\
843.2 \\
\end{array}$ & $\begin{array}{l}809.7 \\
828.6 \\
\end{array}$ & $\begin{array}{l}840.3 \\
857.2 \\
\end{array}$ & $\begin{array}{l}30.6 \\
28.6\end{array}$ & $\begin{array}{l}7.3 \\
6.6 \\
\end{array}$ & $\begin{array}{l}5.3 \\
4.8 \\
\end{array}$ & $\begin{array}{l}28.0 \\
23.4^{*}\end{array}$ & $R=0.995$ \\
\hline $\begin{array}{l}\text { Surface - } \\
\text { Deep Camp }\end{array}$ & $\begin{array}{l}829.8 \\
849.1 \\
\end{array}$ & $\begin{array}{l}815.2 \\
839.4 \\
\end{array}$ & $\begin{array}{l}842.0 \\
857.6 \\
\end{array}$ & $\begin{array}{l}26.8 \\
18.2 \\
\end{array}$ & $\begin{array}{l}8.3 \\
7.0 \\
\end{array}$ & $\begin{array}{l}6.0 \\
4.5 \\
\end{array}$ & $\begin{array}{c}36.3 \\
19.8^{*} \\
\end{array}$ & $\mathrm{R}=0.840$ \\
\hline
\end{tabular}

*At 0.01 level, the variance of the surface measurement series is significantly larger than the variance of the cave measurement series (Null

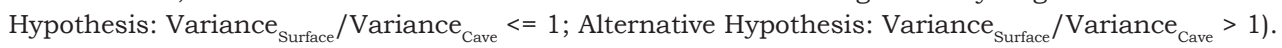

values being at lower levels: Here, average values of surface air pressure vary between 825.4 and 829.8 $\mathrm{hPa}$, while inside the caves, they range from 843.2 to $849.1 \mathrm{hPa}$ for Spooky Hollow and Deep Camp, respectively. The minima of air pressure within the caves lie between 828.6 and $839.4 \mathrm{hPa}$, those on the surface between 809.7 and $815.2 \mathrm{hPa}$; the maxima accordingly between 857.2 and $857.6 \mathrm{hPa}$ (cave) and 840.3 and $842.0 \mathrm{hPa}$ (surface).

While for each measurement location, the absolute displacement of simultaneous air pressure between the surface and the cave seems to be approximately constant over the entire measurement period, it varies considerably between locations. Inside Wind Cave, the average absolute displacements of air pressure range between $4.1 \mathrm{hPa}$ for Pearly Gates and $15.8 \mathrm{hPa}$ for Lakes; inside Jewel Cave, they range between 17.7 $\mathrm{hPa}$ for Spooky Hollow and 19.3 hPa for Deep Camp.

These absolute differences in air pressure are attributable to lower altitudes of the measuring sites inside the caves compared to the respective surface sites as air pressure decreases approximately exponentially with increasing altitude (Halley, 1687). Mathematically, this relationship can be described by the barometric formula (e.g., Rühlmann, 1870; Roedel, 2000). Thus, the higher air pressure inside the caves cannot be related to any cave-specific internal process but is simply caused by the lower altitude of the cave locations compared to the surface and therefore does not provide any relevant information about the behavior of pressure waves and their changes during their propagation through the caves.

\section{Delay}

Besides the absolute displacement due to different altitudes of the measurement locations, our data also reveal a delay of the air pressure signal as the pressure wave travels through the cave. Thus, the pressure signals inside the caves lag the surface signals, and both their minima and maxima are reached later inside the caves than at the surface. Figures $4 \mathrm{a}$ and $4 \mathrm{~b}$ show the positions of the extreme values represented by green lines and their distance from each other for two exemplary sections of the measurement data. For each studied location, the delay of the pressure signal inside the cave $P_{\text {cave }}$ compared to the pressure signal at the surface $P_{\text {surface }}$ seems to be approximately constant and can therefore be determined using cross-correlation analysis:

$$
K(\operatorname{lag})=\int_{-\infty}^{\infty} P_{\text {surface }}(t) P_{\text {cave }}(t+\operatorname{lag}) d t
$$

where the delay is defined as the value lag for which the integral is maximal (i.e., the correlation between the pressure signals $P_{\text {cave }}$ and $P_{\text {surface }}$ is highest).

To compare the thus calculated delays for the different measurement sites, the longest data series with a temporal resolution of $20 \mathrm{~s}$ is chosen for each investigated location. A consistent resolution is important in order to prevent the results of the comparison from being influenced by the resolution. As the delay can only be determined at (relative) extreme values of the pressure waves, the longest measurement series of each measurement location, including the highest number of cyclones and anticyclones, yields the highest possible significance and validity of results.

As shown in Figure 4c, 4e, and Table 3, crosscorrelation analysis of air pressure measurement data from Wind Cave revealed delays of 2:02:20 (Pearly Gates) to 2:21:40 (Lakes). As expected, the delay of the pressure signals increases with increasing distance of the locations from the cave entrance (Fig. 5). Thus, there is a perfect positive Spearman correlation of 1 between the ranked locations and the calculated travel times of the pressure wave. However, considering the large distances between the investigated sites inside Wind Cave (Fig. 2), it is surprising how close the calculated temporal displacements and thus travel 
times are. In regard to their large spatial distance, for example, the displacement between Pearly Gates and Lakes of only 19:20 minutes appears to be very small.

With consideration of the already discussed altitude dependence of the pressure, it is possible to employ the mean difference between external and internal pressure in a simultaneous time period as a proxy for the depth of a site and, therefore, quantitatively analyze the relationship between depth and investigated delay. Those analyses yield a strong linear correlation between the mean difference of air pressure and the delay (Pearson $\mathrm{R}=0.987$ ), as shown in Figure 4e. For every $1 \mathrm{hPa}$ increase in mean distance, the observed delay increases by 1:55 minute. Similarly, in Jewel
Cave, the delay increases with increasing distance from the cave entrance (Fig. 4d, f). Contrary to Wind Cave, however, the differences in calculated delay between the investigated locations here are very large. At Spooky Hollow, cross-correlation analysis yields a lag of 38:20 minutes between the surface and cave pressure signal. At Deep Camp, however, a delay of 10:26:40 hours is found (Table 3). Thus, the temporal shift of air pressure in the deep part of Jewel Cave is on a completely different order of magnitude than at all locations within Wind Cave. Once again, the outstanding characteristics of Deep Camp already observed in the correlations between internal and external pressure are apparent.
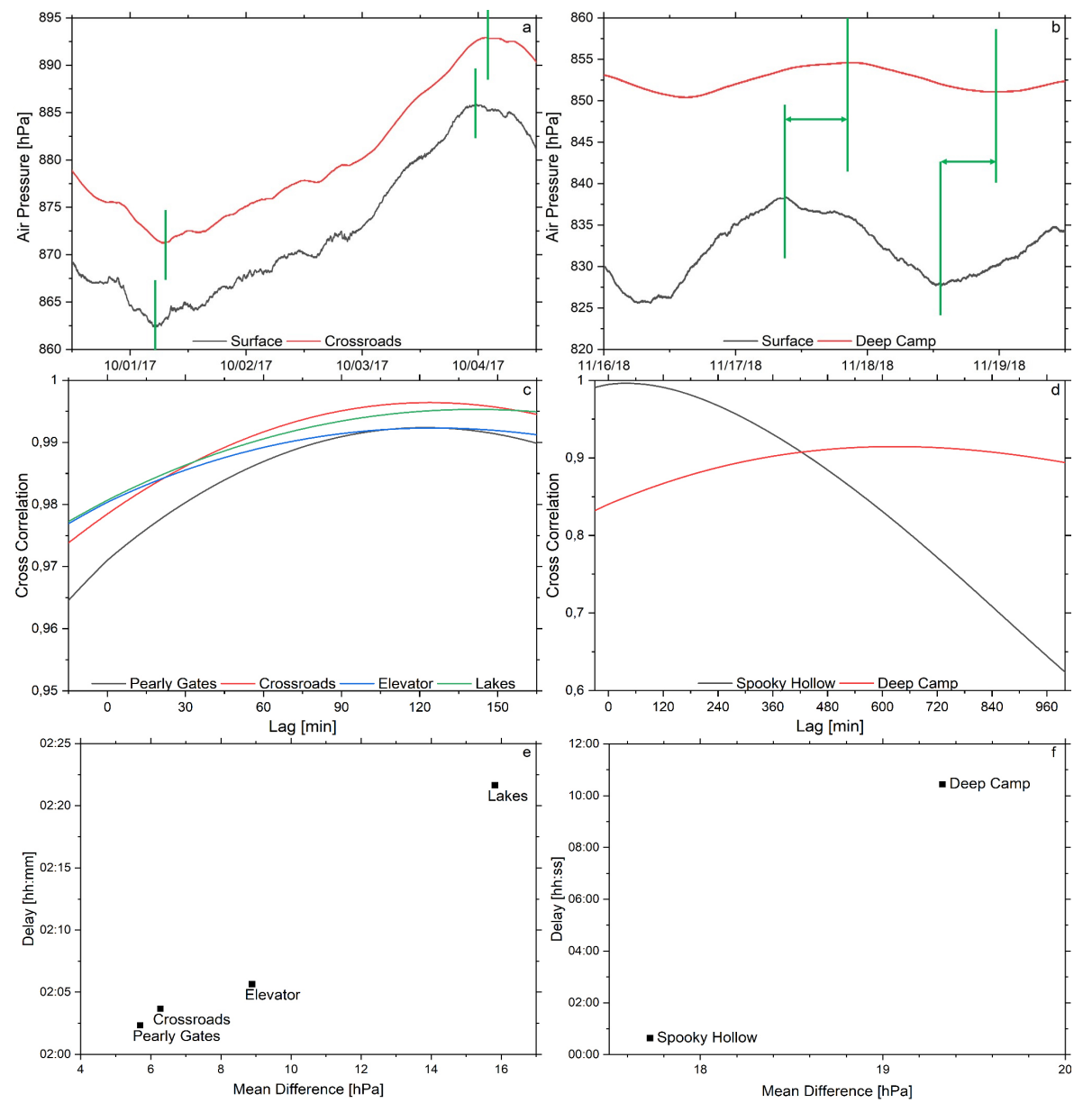

Fig. 4. Top: Exemplary extracts of simultaneous measurement series from Crossroads, Wind Cave (a) and Deep Camp, Jewel Camp (b) and their respective surface sites. The green lines indicate the position of selected pressure extremes and thus their temporal shift: Within the caves, both minimum and maximum points of the pressure signal are reached later than at the surfaces. Middle: Results of cross-correlation analyses of simultaneous pressure series in Wind Cave (c) and Jewel Cave (d) and their respective surface sites: The calculated lags of the pressure signals at all investigated locations within Wind Cave (Pearly Gates, Crossroads, Elevator, Lakes) are very close to each other with values between 02:02:20 and 02:21:39, while they vary significantly throughout Jewel Cave with values of 00:38:20 at Spooky Hollow and 10:26:40 at Deep Camp. Bottom: Calculated delay of the cave pressure signal compared to the surface pressure signal as a function of the mean difference between surface and cave air pressure at the respective measurement location used as a proxy for the distance to the cave entrance: Strong linear relationship within Wind Cave $(R=0.987)$ at an average slope of 1:55 minute/hPa $(e)$; significantly higher slope of 6:07:08 h/hPa between Spooky Hollow and Deep Camp (f).

In Wind Cave, the entrance of the cave seems to be the strongest obstacle slowing down the pressure wave. Once the pressure wave has passed the small opening and narrow entrance area, it propagates through the cave quite fast, resulting in only small differences in travel times between the investigated locations. Inside Jewel Cave, however, the opening and entrance area do not seem to slow down pressure wave propagation significantly, as indicated by the rather small delay at Spooky Hollow compared to the surface signal. The large difference between the temporal delay at Spooky Hollow and Deep Camp, however, indicates that within Jewel Cave, it is not the opening that is the most constraining factor on the pressure wave. 
Instead, the pressure wave is significantly slowed down only inside the cave as it travels to the deep parts. These observed differences in pressure wave behavior between Wind Cave and Jewel Cave can be attributed to different morphological characteristics of the two caves: The greater density of passage volume per rock volume in Wind Cave allows the pressure wave to travel through the cave more easily while the smaller density of passages inside Jewel Cave restricts and decelerates pressure wave propagation.

The exceptionally long delay of the pressure signal at Deep Camp inside Jewel Cave, which cannot be observed at any location inside Wind Cave, also corresponds to the results of Conn (1966), whose measurements and analyses revealed a significantly longer time lag between a peak of external air pressure and the thus induced change of wind direction at the opening of Jewel Cave compared to Wind Cave. Moreover, these findings can also provide a convincing explanation for the phenomenon described in Pflitsch et al. (2010) that the periods of consistent airflow at the opening of Jewel Cave are much longer than those at Wind Cave.

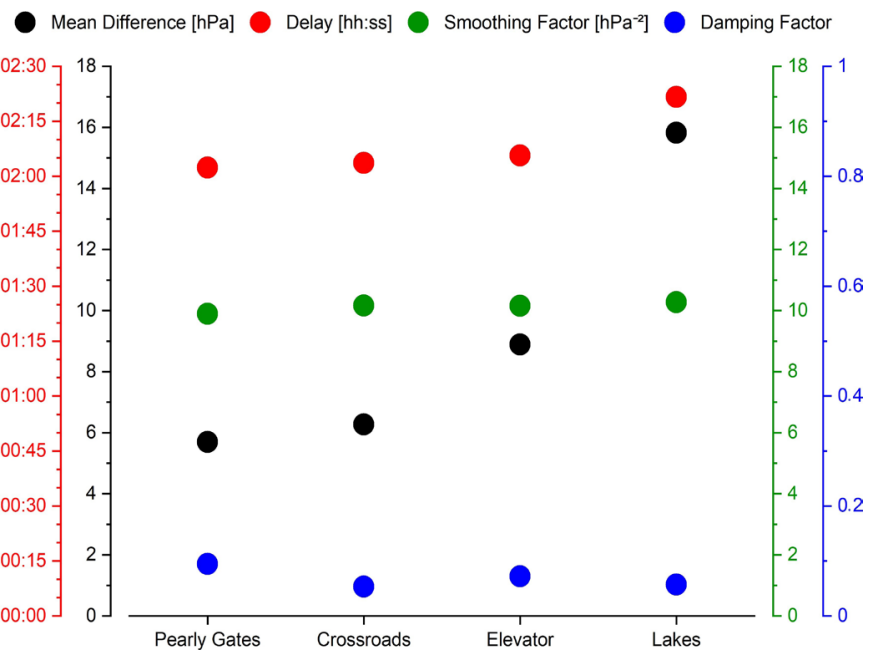

Fig. 5. Spatial comparison of mean difference, delay, smoothing factor, and damping factor as quantitative indices for the differences between cave and surface pressure at all investigated locations within Wind Cave in ascending distance from the entrance.

\section{Smoothing}

Air pressure signals inside Wind Cave and Jewel Cave were also found to be smoothed compared to signals at their surfaces. A comparison reveals that large atmospheric pressure systems are transmitted into the caves, whereas small pressure fluctuations are lost in the cave signals. Highlighted by green circles, Figures $6 \mathrm{a}$ and $6 \mathrm{~b}$ show numerous small fluctuations to occur in the surface signals, which cannot be found in the cave signal. Large atmospheric pressure systems, on the other hand, are transmitted into the cave and can therefore also be detected in the cave pressure signal.

Atmospheric surface pressure in the Black Hills, where Wind Cave and Jewel Cave are located, is mainly influenced by irregular alternating highand low-pressure systems (i.e., anticyclones and cyclones), which move across the region in a westerly direction. These large pressure systems, however, are
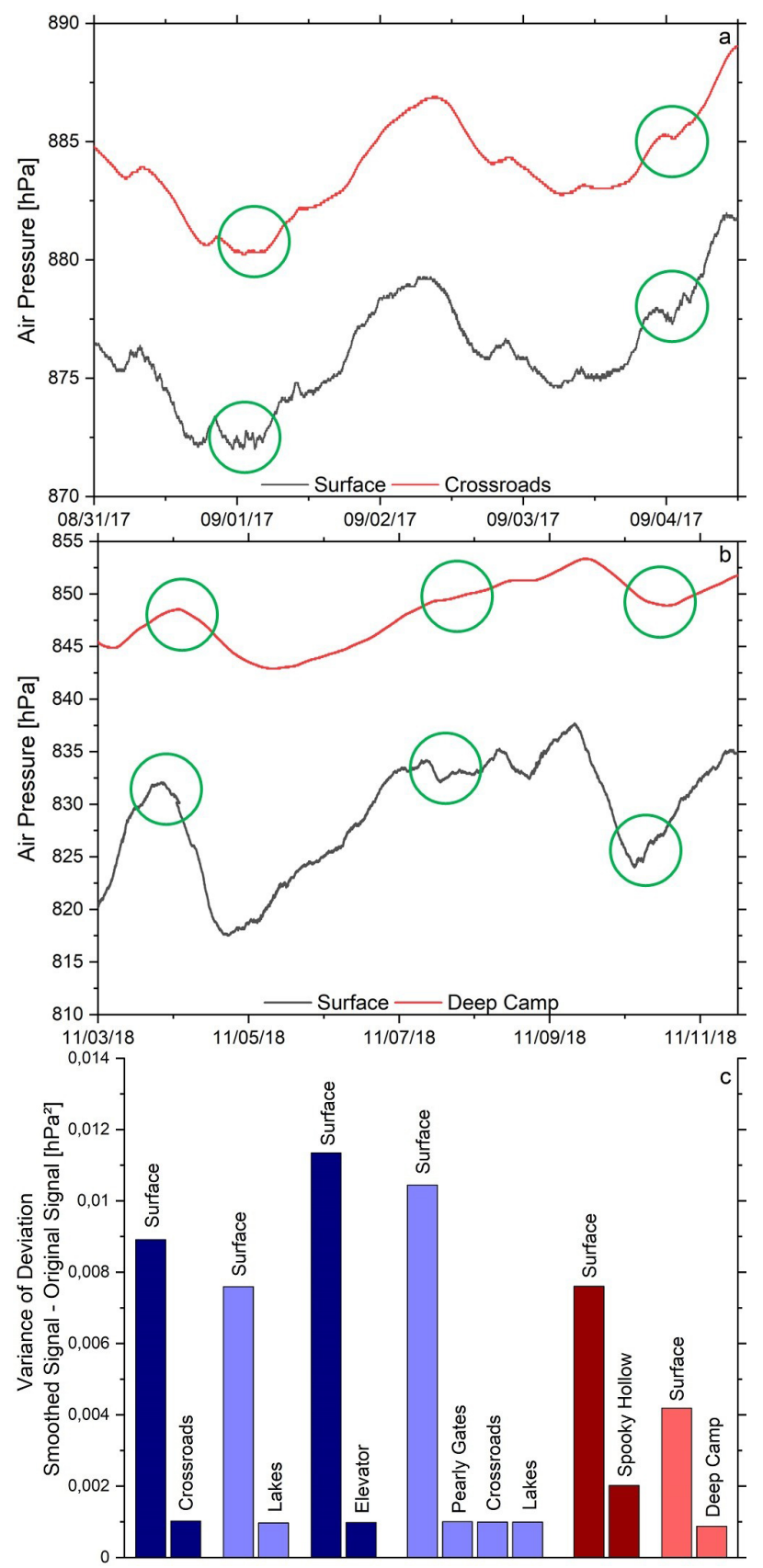

Fig. 6. Top and Middle: Exemplary extracts of simultaneous measurement series from Crossroads, Wind Cave (a) and Deep Camp, Jewel Camp (b) (red) and their respective surface sites (grey). The green circles indicate corresponding sections of the internal and external pressure signal: Low amplitude, highfrequency fluctuations (visible as small "spikes" of the grey lines) are only observed in the surface pressure signal and are not transmitted into the cave; larger atmospheric pressure systems with a larger amplitude and lower frequency, however, can also be observed inside the caves. Bottom: Variance of the deviation of each air pressure signal smoothed with a running average of one hour from the original signal as a measure of roughness of air pressure: For all measurement series, air pressure signals inside the caves are significantly smoothed compared to simultaneous surface pressure signals. Inside Wind Cave, the roughness of air pressure is very similar at all investigated locations; inside Jewel Cave, the pressure signal at Deep Camp is much smoother than at Spooky Hollow.

superimposed by numerous small fluctuations with much smaller amplitudes and higher frequencies generated by a variety of atmospheric phenomena, including ocean wave interactions (Donn \& Rind, 1972; Hupe et al., 2019; De Carlo et al., 2021), thermally induced atmospheric gravity waves (Nappo, 2002), airflow turbulence (Sigmon et al., 1983, 1984; 
Clarke \& Waddington, 1991; Hauf et al., 1996; Mohr et al., 2016), and local winds blowing over or around topographic features (Massman, 2005). If atmospheric pressure waves are transmitted into and propagate through the three-dimensional mazes of Wind Cave and Jewel Cave, they do not only travel through large halls and wide tunnels but also through a multitude of narrow gaps and fissures. Especially in areas with a large ratio of rock surface to air volume, strong frictional losses at the rugged rock surfaces occur. If the pressure waves continue to propagation through the complex labyrinth of the cave, they overlap in such a way that smaller atmospheric pressure fluctuations partly cancel each other out and the pressure signal appears smoothed. However, this process of destructive interference alone cannot explain the strong smoothing, which can be observed near the entrance of Wind Cave.

Table 3. Quantitative indices of systematic differences between cave and surface pressure at studied sites within Wind Cave and Jewel Cave, each in ascending distance from the entrance.

\begin{tabular}{|l|c|c|c|c|c|}
\hline \multicolumn{1}{|c|}{ Locations } & Correlation R & $\begin{array}{c}\text { Mean difference } \\
{[\mathbf{h P a}]}\end{array}$ & Delay [hh:mm:ss] & $\begin{array}{c}\text { Smoothing factor } \\
{\left[\mathbf{h P a}^{-2}\right]}\end{array}$ & Damping factor \\
\hline Wind Cave - Pearly Gates & 0.971 & 5.7 & $02: 02: 20$ & 9.01 & 0.095 \\
\hline Wind Cave - Crossroads & 0.979 & 6.3 & $02: 03: 40$ & 10.167 & 0.053 \\
\hline Wind Cave - Elevator & 0.980 & 8.9 & $02: 05: 40$ & 10.157 & 0.072 \\
\hline Wind Cave - Lakes & 0.981 & 15.8 & $02: 21: 40$ & 10.273 & 0.057 \\
\hline Jewel Cave - Spooky Hollow & 0.995 & 17.7 & $00: 38: 20$ & 4.951 & 0.066 \\
\hline Jewel Cave - Deep Camp & 0.840 & 19.3 & $10: 26: 40$ & 11.406 & 0.320 \\
\hline
\end{tabular}

In order to describe this visual observation quantitatively, the moving average of one hour is calculated for each observed air pressure signal to smooth the high-frequency components of air pressure without smoothing the longer-term variations. The variance of the deviation of the thus smoothed air pressure signal from the original signal then provides a measure of roughness below one hour. A large variance indicates a rough signal, whereas a smooth signal is characterized by a small variance.

The results of this quantitative analysis support the impression already gained visually: at all investigated locations, the roughness of the pressure signal inside the caves is lower than during the same period at the surface, indicating smoothing as the pressure waves travel through Wind Cave and Jewel Cave. Between the locations inside the caves, however, the differences in roughness are relatively small. Figure $6 \mathrm{c}$ summarizes these results.

Based on the measure of roughness introduced before, a smoothing factor can be calculated, which indicates the strength of smoothing inside the caves:

$$
\text { Smoothing Factor }=\frac{1}{\operatorname{Var}\left[P(t)-P_{M A}^{\text {1hour }}(t)\right]} * 100
$$

where $P(t)$ is the original pressure signal and $P_{M A}^{1 \text { hour }}(t)$ is the moving average of the pressure signal averaged by 1 hour.

For spatial analysis, again the longest measurement series of each investigated location with a temporal resolution of $20 \mathrm{~s}$ is selected (Table 3). In contrast to the previously analyzed absolute pressure difference and the delay of the pressure signal, the strength of the smoothing effect inside Wind Cave does not depend on the distance to the cave opening. Thus, all calculated smoothing factors are very similar, and no clear spatial trend can be found (Fig. 5, Table 3). Consequently, it can be concluded that the whole smoothing process occurs at the entrance and the uppermost part of
Wind Cave above Pearly Gates. As soon as a "saturation degree" of smoothing is reached, no further changes in this respect can be observed. Inside Jewel Cave, however, the air pressure signal at Deep Camp is much smoother than at Spooky Hollow (Table 3), indicating the strongest smoothing to occur in the deeper parts of the cave between Spooky Hollow and Deep Camp.

\section{Damping}

The last systematic change between the surface and cave pressure signals identified is a damping effect on pressure waves inside the caves. Consequently, both the extreme highs and lows of the surface pressure signals are attenuated inside the caves resulting in a lower air pressure range.

Figure 7a clearly demonstrates that the pressure difference between two successive extreme values is significantly smaller inside the caves than at the surface. This observation is also supported by the corresponding boxplots (Fig. 7c), indicating a decreased range of pressure inside the cave compared to the surface for all investigated locations. As shown in Figure $7 \mathrm{~b}$ and $7 \mathrm{~d}$, this effect becomes particularly clear if the absolute difference caused by altitude differences is removed from the data and measured absolute air pressure $\mathrm{P}_{\mathrm{abs}}$ is converted into relative air pressure $\mathrm{P}_{\text {rel }}$ by subtracting the mean of each time series from its individual values:

$$
P_{r e l}=P_{a b s}-\operatorname{mean}\left(P_{a b s}\right)
$$

This process shifts the mean of each measurement series to 0 , while the measures of statistical dispersion (i.e., interquartile range IQR, range, standard deviation, variance) are not affected.

The excerpt of the pressure measurements at the surface and at Lakes presented in Figure $7 \mathrm{~b}$ shows that in both directions, the extreme values of the atmospheric pressure are never reached inside the cave. Simply put, inside the cave, the highs are lower, and the lows are higher. 
The observed damping of air pressure inside Wind Cave and Jewel Cave is caused by the relatively long response time of the two cave systems compared to the time scale of external atmospheric pressure changes. As introduced by Conn (1966), the behavior of air pressure inside barometric caves can be described by a simple "balloon" model: A void (balloon) with volume $\mathrm{V}$ is connected to a driving force (i.e., air pressure variations in the external atmosphere) via a conduit (i.e., the small opening and narrow entrance area of the cave) with a characteristic length, diameter and roughness containing turbulent airflow and providing aeraulic resistance. According to this model, the response time of a cave increases with increasing volume and increasing air resistance.

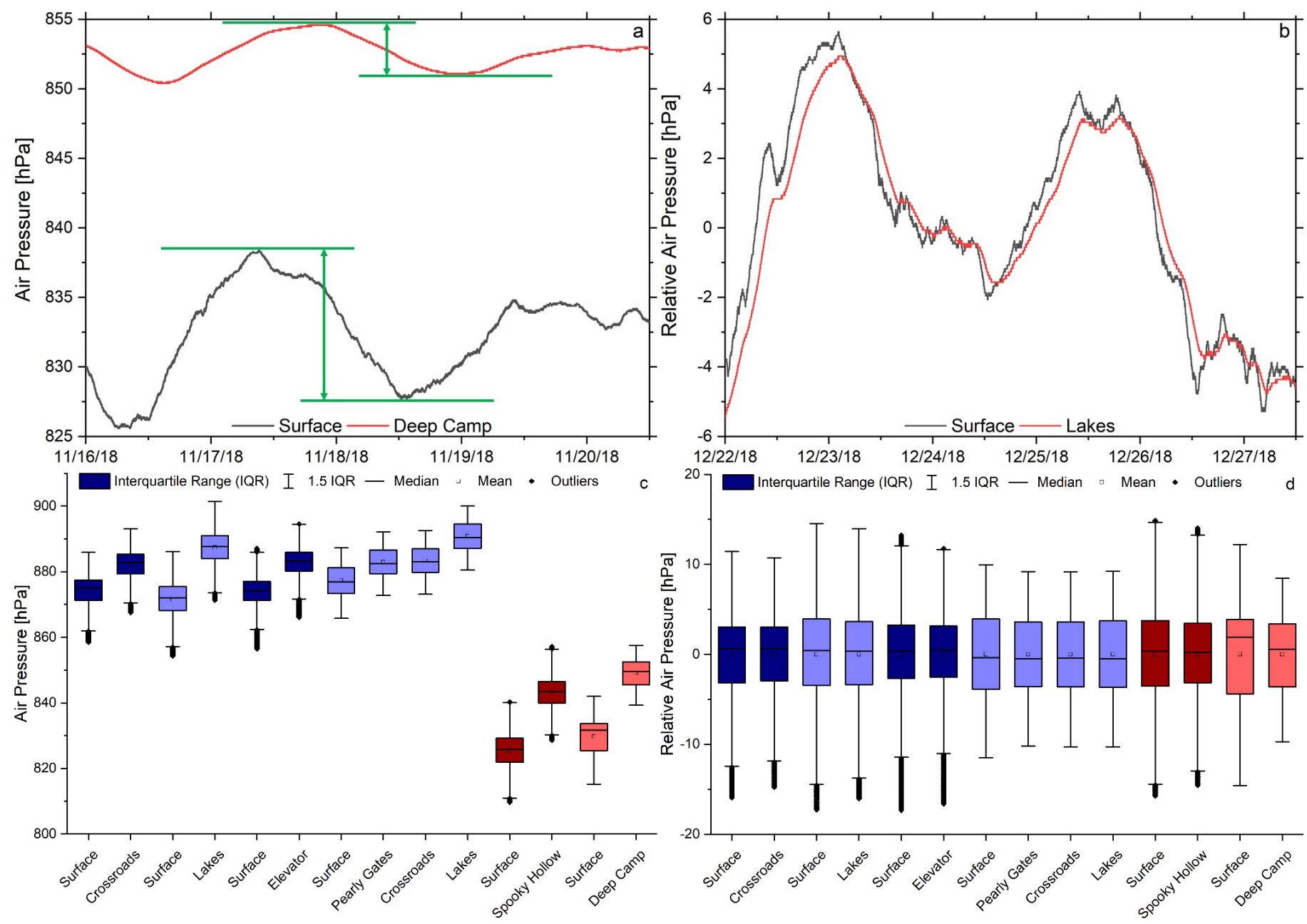

Fig. 7. Top: Exemplary extract of simultaneous measurement series of (a) absolute air pressure from Deep Camp, Jewel Cave and (b) relative air pressure from Lakes, Wind Cave (red), and the respective surface sites (grey). The horizontal green lines show the position of two successive extreme values of internal and external pressure; the vertical arrows indicate their distance. Inside the caves, the amplitudes of the pressure signals are smaller compared to the surface signals. Bottom: Boxplot diagrams of absolute (c) and relative (d) air pressure; identical color shades indicate simultaneous measurements. For all measurement series, both the IQR and the total range of air pressure inside Wind Cave and Jewel Cave are smaller than on the respective surface sites indicating dampening of air pressure inside the caves.

If surface air pressure increases, compensating airflow into the cave is induced, causing a delayed increase in air pressure within the cave. However, before cave air pressure reaches the maximum of surface air pressure, surface pressure has started to fall again, causing a reversal of airflow direction and, therefore, a drop of air pressure inside the cave. Due to the constant alternation of cyclones and anticyclones in the outside atmosphere, the driving surface air pressure is changing faster than the cave pressure can equilibrate, leading to smaller internal pressure amplitudes.

Both the described smoothing and damping of the external air pressure signal in the cave are based on the same physical process acting on different time scales: Smoothing is the damping of the high-frequency component of the driving surface air pressure signal (small-scale variations), whereas damping is the damping of the low-frequency component of the driving surface pressure signal (alternating large-scale pressure systems). In accordance with Conn's (1966) balloon model, the cave behaves as a low-pass filter on the air pressure signals: High-frequency signals will be filtered out and therefore smoothed, whereas low-frequency signals will pass through into the cave. The cut-off frequency depends on the timescale over which the cave can equilibrate to external air pressure changes. Variations occurring over timescales shorter than this equilibration time will be filtered; variations occurring over timescales longer than the equilibration time will pass through. Therefore, the decisive factor is the dimensionless ratio of cave pressure response time to the timescale of variation in external atmospheric air pressure. This concept of a low-pass filter even applies to highly complex cave systems like Jewel Cave and Wind Cave, which can be 
described as a three-dimensional series of voids and conduits. It can explain both the observed smoothing and damping of the internal pressure signals.

Based on the quotient of the internal and external pressure ranges, a damping factor can be determined to compare the degree of damping at different locations:

$$
\text { Damping Factor }=1-\frac{\text { Range }_{\text {cave }}}{\text { Range }_{\text {surface }}}
$$

Comparing the damping factors thus determined for the measurement locations inside Wind Cave, no correlation between the position and the degree of damping can be found (Table 3, Fig. 5). Surprisingly, the strongest damping does not occur at the deepest location inside the cave (Lakes), but at Pearly Gates in the upper part of the cave. Thus, it appears that the distance traveled by the pressure wave is not the decisive factor, but rather local characteristics, which influence the degree of damping.

Deep Camp inside Jewel Cave again differs greatly from all other investigated locations as it exhibits an extremely high damping factor (Table 3). Once again, the exceptional character of Deep Camp in terms of air pressure becomes apparent.

Together, the described smoothing and damping processes also affect the descriptive statistics and lead to a significant reduction of the standard deviation and variance inside the caves compared to the outside atmosphere (Table 2).

\section{CONCLUSIONS}

This study presents the first attempt to describe the behavior of air pressure waves inside barometric caves and to identify and discuss the related speleoclimatological processes. Compared to simultaneous measurements at the surface, air pressure at all investigated locations inside the caves was found to be (1) absolutely displaced due to lower altitudes inside the caves, (2) delayed due to a deceleration of the pressure wave at the entrances and at constrictions within the caves, (3) smoothed, and (4) damped due to long cave pressure response times relative to the timescale of atmospheric pressure variations.

Surprisingly, inside Wind Cave, the distance of the investigated sites from the surface did not affect the strength of the identified speleological processes and thus induced changes of the pressure signal as strongly as previously assumed. Instead, the small opening and the entrance area of the cave provide the strongest obstacles at which pressure waves are delayed, smoothed, and damped. In Jewel Cave, by contrast, a large majority of these changes to air pressure signals occur the deeper parts of the cave, where a series of constrictions causes a highly damped and lagged signal.

It is only through the speleoclimatological processes identified and described in this study that pressure gradients between the inside of barometric caves and the outside atmosphere can develop, which then induce the characteristic compensating currents. Considering the fundamental importance of underground airflow resulting from these pressure gradients for almost all elements of speleoclimatology, including air temperature, humidity, and $\mathrm{CO}_{2}$ dynamics, as well as for management and conservation purposes, this study lays the groundwork for an improved understanding of numerous aspects of climate systems inside barometric caves.

\section{ACKNOWLEDGEMENTS}

This study was financially supported by the Ruhr-University Research School PLUS, funded by Germany's Excellence Initiative [DFG GSC 98/3], and the German Academic Scholarship Foundation (Studienstiftung des deutschen Volkes). We also extend our sincere thanks to Wind Cave National Park and Jewel Cave National Monument staff for their tremendous support during the cave fieldwork and wish to thank Charlotte Hueser for her help with the digital illustration of a barometric cave. Finally, we thank the reviewers, whose constructive comments and suggestions greatly increased the quality and relevance of the final paper.

Authorship statement: AG and AP designed and directed the study; AG, DA, MO, and AP performed the measurements and carried out the fieldwork. AG analyzed and interpreted the data and created the figures. AG wrote the paper; DA, MO, and AP reviewed the paper. All authors read and approved the final manuscript.

\section{REFERENCES}

Bakalowicz, M.J., Ford, D.C., Miller, T.E., Palmer, A.N., Palmer, M.V., 1987. Thermal genesis of dissolution caves in the Black Hills, South Dakota. Geological Society of America Bulletin, 99, 729-738.

https://doi.org/10.1130/0016-7606(1987)99<729:TG ODCI $>2.0 . \mathrm{CO} ; 2$

Bögli, A., 1980. Karst hydrology and physical speleology. Springer, Berlin, p. 214-226.

https://doi.org/10.1007/978-3-642-67669-7_15

Breitenbach, S.F.M., Lechleitner, F.A., Meyer, H., Diengdoh, G., Mattey, D., Marwan, N., 2015. Cave ventilation and rainfall signals in dripwater in a monsoonal setting - a monitoring study from NE India. Chemical Geology, 402, 111-124.

https://doi.org/10.1016/j.chemgeo.2015.03.011

Clarke, G.K.C., Waddington, E.D., 1991. A threedimensional theory of wind pumping. Journal of Glaciology, 37, 89-96.

https://doi.org/10.1017/S0022143000042830

Conn, H.W., 1966. Barometric wind in Wind and Jewel caves, South Dakota. NSS Bulletin, 28, 55-69.

De Carlo, M., Hupe, P., Le Pichon, A., Ceranna, L., Ardhuin, F., 2021. Global microbarom patterns: A first confirmation of the theory for source and propagation. Geophysical Research Letters, 48, 1-10. https://doi.org/10.1029/2020GL090163

De Freitas, C.R., 2010. The role and importance of cave microclimate in the sustainable use and management of show caves. Acta Carsologica, 39, 477-489.

https://doi.org/10.3986/ac.v39i3.77

De Freitas, C.R., Littlejohn, R.N., 1987. Cave climate: Assessment of heat and moisture exchange. Journal of 
Climatology, 7, 553-569.

https://doi.org/10.1002/joc.3370070604

De Freitas, C.R., Littlejohn, R.N., Clarkson, T.S., Kristament, I.S., 1982. Cave climate: Assessment of airflow and ventilation. Journal of Climatology, 2, 383397. https://doi.org/10.1002/joc.3370020408

Donn, W.L., Rind, D., 1972. Microbaroms and the temperature and wind of the upper atmosphere. Journal of the Atmospheric Sciences, 29, 156-172.

https://doi.org/10.1175/1520-0469(1972)029\%3C01 56:MATTAW\%3E2.0.CO;2

Dublyansky, V.N., Dublyansky, Y.V., 1998. The problem of condensation in karst studies. Journal of Cave and Karst Studies, 60, 3-17.

Fernández-Cortés, A., Calaforra, J.M., Sánchez-Martos, F., 2006. Spatiotemporal analysis of air conditions as a tool for the environmental management of a show cave (Cueva del Agua, Spain). Atmospheric Environment, 40, 7378-7394.

https://doi.org/10.1016/j.atmosenv.2006.06.045

Halley, E., 1687. A discourse of the rule of the decrease of the height of the mercury in the barometer, according as places are elevated above the surface of the Earth, with an attempt to discover the true reason of the rising and falling of the mercury, upon change of weather. Philosophical Transactions of the Royal Society of London, 16, 104-116.

https://doi.org/10.1098/rstl.1686.0017

Hauf, T., Finke, U., Neisser, J., Bull, G., Stangenberg, J.-G., 1996. A ground-based network for atmospheric pressure fluctuations. Journal of Atmospheric and Oceanic Technology, 13, 1001-1023.

https://doi.org/10.1175/1520-0426(1996)013\%3C10 01:AGBNFA\%3E2.0.CO;2

Hupe, P., Ceranna, L., Pilger, C., De Carlo, M., Le Pichon, A., Kaifler, B., Rapp, M., 2019. Assessing middle atmosphere weather models using infrasound detections from microbaroms. Geophysical Journal International, 216, 1761-1767. https://doi.org/10.1093/gji/ggy520

KellerLynn, K., 2009. Wind Cave National Park Geologic Resources Inventory Report: Natural Resource Report NPS/NRPC/GRD/NRR-2009/087. National Park Service, Denver, Colorado, $48 \mathrm{p}$.

Kłys, G., Wołoszyn, B.W., 2005. The influence of weather and interior microclimate on the hibernation of common long-eared bat (Plecotus auritus). Nature Journal, 38, 57-68.

Lario, J., Soler, V., 2010. Microclimate monitoring of Pozalagua Cave (Vizcaya, Spain): Application to management and protection of show caves. Journal of Cave and Karst Studies, 72, 169-180.

https://doi.org/10.4311/jcks20091sc0093

Mammola, S., Piano, E., Giachino, P.M., Isaia, M., 2015. Seasonal dynamics and micro-climatic preference of two Alpine endemic hypogean beetles. International Journal of Speleology, 44(3), 239-249.

http://doi.org/10.5038/1827-806X.44.3.3

Massman, W.J., 2005. Advective transport of $\mathrm{CO}_{2}$ in permeable media induced by atmospheric pressure fluctuations. AGU Fall Meeting Abstracts, 2005, B52A-08.

Mohr, M., Laemmel, T., Maier, M., Schindler, D., 2016. Analysis of air pressure fluctuations and topsoil gas concentrations within a Scots Pine Forest. Atmosphere, 7, 125. https://doi.org/10.3390/atmos7100125

Moore, G.W., Nicholas, B.G., 1964. Speleology: the study of caves. DC Heath \& Company, Boston, 120 p.

Nappo, C.J., 2002. An introduction to atmospheric gravity waves. International Geophysics Series, San Diego, 276 p.

Palmer, A.N., 2016. Karst and caves of the Black Hills, South Dakota, USA. Boletín Geológico y Minero, 127, 67-78.
Palmer, A.N., Palmer, M.V., 1989. Geologic history of the Black Hills caves. NSS Bulletin, 51, 72-99.

Palmer, A.N., Palmer, M.V., Paces, J.B., 2016. Geologic history of the Black Hills caves, South Dakota. In: Feinberg, J.M., Gao, Y., Alexander, E.C. (Eds.), Caves and karst across time. Geological Society of America, p. 87-101. https://doi.org/10.1130/2015.2516(07)

Pflitsch, A., Ringeis, J., 2009. Jewel Cave and Wind Cave vs. one Black Hills cave system. In: White, W.B. (Ed.), Proceedings of the 15th International Congress of Speleology, Kerrville, Texas, p. 1632-1636.

Pflitsch, A., Wiles, M., Horrocks, R.D., Piasecki, J., Ringeis, J., 2010. Dynamic climatologic processes of barometric cave systems using the example of Jewel Cave and Wind Cave in South Dakota, USA. Acta Carsologica, 39(3), 449-462.

https://doi.org/10.3986/ac.v39i3.75

Ravbar, N., Kosutnik, J., 2014. Variations of karst underground air temperature induced by various factors (Cave of Županova jama, Central Slovenia). Theoretical and Applied Climatology, 116, 327-341. https://doi.org/10.1007/s00704-013-0955-4

Ringeis, J., Pflitsch, A., Piasecki, J., 2007. Luftdruckund Strömungsverhältnisse barometrischer Höhlen - Untersuchungen an der Wind Cave und der Jewel Cave in Süd Dakota, USA. In: Speläogruppe Letmathe - Verein für Höhlenkunde in Westfalen e. V. (Ed.), Speläologisches Jahrbuch 2007: Sonderausgabe anlässlich der 47. Jahrestagung des Verbandes der deutschen Höhlen- und Karstforscher (VdHK) e. V. in Iserlohn-Letmathe vom 17. bis 20. Mai 2007. Iserlohn (Deutschland), p. 16-19.

Roedel, W., 2000. Physik unserer Umwelt: Die Atmosphäre. Springer, Berlin, $498 \mathrm{p}$.

https://doi.org/10.1007/978-3-662-09325-2

Rühlmann, R., 1870. Die barometrischen Höhenmessungen und ihre Bedeutung für die Physik der Atmosphäre. Barth, Leipzig.

Russell, M.J., MacLean, V.L., 2008. Management issues in a Tasmanian tourist cave: potential microclimatic impacts of cave modifications. Journal of Environmental Management, 87, 474-483. https://doi.org/10.1016/j.jenvman.2007.01.012

Sánchez-Cañete, E.P., Serrano-Ortiz, P., Domingo, F., Kowalski, A.S., 2013. Cave ventilation is influenced by variations in the $\mathrm{CO}_{2}$-dependent virtual temperature. International Journal of Speleology, 42(1), 1-8. http://doi.org/10.5038/1827-806X.42.1.1

Sigmon, J.T., Knoerr, K.R., Shaughnessy, E.J., 1983. Microscale pressure fluctuations in a mature deciduous forest. Boundary-Layer Meteorology, 27, 345-358. https://doi.org/10.1007/BF02033744

Sigmon, J.T., Knoerr, K.R., Shaughnessy, E.J., 1984. Leaf emergence and flow-through effects on mean windspeed profiles and microscale pressure fluctuations in a deciduous forest. Agricultural and Forest Meteorology, 31, 329-337.

https://doi.org/10.1016/0168-1923(84)90045-5

Tuttle, M.D., Stevenson, D.E., 1977. Variation in the cave environment and its biological implications. In: Zuber, R., Chester, J., Gilbert, S., Rhodes, D. (Eds.), National Cave Management Symposium Proceedings. Albuquerque, New Mexico, USA, p. 108-121.

Vieten, R., Winter, A., Warken, S., Schröder-Ritzrau, A., Miller, T.E., Scholz, D., 2016. Seasonal temperature variations controlling cave ventilation processes in Cueva Larga, Puerto Rico. International Journal of Speleology, 45(3), 259-273.

http://doi.org/10.5038/1827-806X.45.3.1983 